Published in Educational Psychology. 22 (1), 75-91

\title{
Cognitive and psychological factors underlying secondary school students' feelings towards group work ${ }^{123}$
}

\author{
Robert H. Cantwell \& Beverley Andrews \\ Faculty of Education \\ University of Newcastle \\ NSW, Australia
}

\begin{abstract}
290 secondary school students from Years 7, 9 and 11 completed questionnaires relating to motivational goals, metacognitive awareness, need for affiliation, social anxiety and feelings towards group work. Factor analysis revealed three attitudes towards participation in group work: a preference for group environments, a preference for individual work environments, and a sense of discomfort in group environments. Students reporting a preference for group work also indicated higher levels of sociability, lower levels of social anxiety, stronger mastery and performance goals and greater levels of metacognitive awareness. Students expressing a preference for individual work environments reported lower levels of sociability and higher levels of social anxiety, but were not differentiated on any of the cognitive measures. Students reporting discomfort in groups similarly reported enhanced levels of social anxiety combined with lower levels of sociability, but also indicated lower levels of metacognitive awareness. Results are discussed in the context of current theoretical and empirical work on group-based learning.
\end{abstract}

This paper examines the role of individual differences in explaining secondary students' attitudes towards engaging in group-based learning. There is a strong literature suggestive of benefits to students of group based learning (for a review see Slavin, 1996). From a Vygotskian perspective, there are clear and well documented cognitive advantages to establishing group based learning environments. King (1997), for example, points to the metacognitive advantages of using group learning contexts as a means of facilitating higher-order learning. However, we suggest that little attention in this literature has been given to the underlying cognitive and psychological factors that may influence both the willingness of students to take part in group learning, and the degree to which group learning might effectively occur. We propose that the use of group-based learning is premised on three assumptions: firstly that all children are comfortable with the idea and processes of group learning, secondly, that all children possess the requisite cognitive and psychological attributes and abilities appropriate to functioning in a group learning context, and thirdly, that there are no developmental differences in children's capacity to function in group learning environments.

At the cognitive level, we address two potential sources of individual difference: motivational goals and metacognitive abilities. Group learning necessarily deals in complexity of two kinds. Under the 
Vygotskian assumptions, learning occurs under the impetus of socially created cognitive dissonance (King, 1997). The interplay of competing ideas and their resolution through socially mediated consensus implies on the part of all group members both a preparedness to engage in task-centred group discussion, and the capacity to effectively marshal and regulate the strategies necessary for more complex, higher-order learning. Thus we suggest that the quality of engagement in group working will in part reflect

kinds of motivational goals brought to the group learning context and task, in conjunction with the quality of metacognitive knowledge brought to the context and task, will provide major sources of individual difference in students preparedness to engage in group learning. Recent research into achievement goals (Archer, 1994; Ames \& Archer, 1988), for example, has suggested that students may ascribe to several kinds of goals, ranging from the content and task- centred "mastery" goals, to more competitively ego-oriented "performance" goals and academically detached "alienation" goals. Each of these motivational constructs may be presumed to drive attitudes towards group learning in different ways. Mastery-oriented students, for example, may be expected to both perceive and actively construct a climate in which group-based learning acts to focus on taskdevelopment and completion. On the other hand, students oriented more towards performance goals may, should group interaction be perceived as threatening, see immediate public disclosure as a disincentive to group participation. Conversely, performance oriented students may, where group disclosure is not perceived as invoking ego-threatening consequences, find the group context egoenhancing and therefore be more willing to be involved. For students experiencing stronger feelings of academic alienation, the possibility of group pressure to participate may bias these individuals towards a greater preference for individual rather than group-centred learning environments.

The second cognitive dimension considered in this study involves levels of metacognitive awareness. Group based learning inevitably involves the individual in the management of complexity - both in terms of the content demands imposed by the socially invoked cognitive dissonance, and in terms of the development of more complex prosocial behaviours. Fantuzzo, Riggio, Connelly and Dimeff (1989) identified three essential student characteristics for effective group-based learning: preparedness to teach a peer, to actually teach a peer, and to acknowledge accountability for teaching a peer. Whether younger children are developmentally capable of taking the alternative perspectives these contexts presume raises a further issue for investigation. Studies of the development of metacognitive awareness have indicated that it may not be until midadolescence that children have the cognitive maturity to either meaningfully reflect upon their own strategic learning (eg Cantwell, 1998) or to effectively take the role of instructor (eg Schwanenflugel, Fabricius \& Alexander, 1994; Zimmermann, 1995). It may well be the case, then, that as students reflect a greater level of metacognitive awareness that the preparedness and ability to engage in group-based learning increases. 
Additionally, the transition from individual to group-based instruction introduces an extra socialpsychological variable into the learning context. It would seem reasonable to assume that personality traits such as level of sociability may influence not only the way in which individuals conduct themselves in group learning contexts, but may indeed influence their preparedness to engage in group-based learning at all. One measure of such sociability is Jackson's (1974) Need for Affiliation. According to this research, people indicating a high need for affiliation are more likely to participate in co-operative, non-competitive activities and are more biassed towards closer, friendly relationships with others (Klein \& Pridemore, 1992). In a study of the outcomes of group versus individual learning among undergraduate students, for example, Klein and Pridemore (1992) found that high need for affiliation individuals working alone performed more poorly than all other groups. Moreover, it may also be the case that those students who feel comfortable working in reasonably intimate group contexts will be more likely to positively respond to the group environment than would be the case of those students for whom social interactions are often strategically quite problematic. Fantuzzo et al (1989) included psychological adjustment in their analysis of the influence of reciprocal peer tutoring on learning amongst undergraduate students. Using the Watson and Friend (1969) measures of Fear of Negative Evaluation (FNE) and Social Avoidance and Distress (SAD), Fantuzzo et al (1989) found both measures of psychological adjustment to group learning to be reduced only in those groups where the group processes were structured to allow equal access to both instructional and learning roles. In the unstructured group condition, the capacity of students high on the FNE and SAD measures to compensate for the less predictable and less certain social demands of group work resulted in a significantly higher reported level of distress in comparison to the structured group as well as the independent work groups. Subjective feelings of distress appear then to be an important mediating influence on the effectiveness of group-based instruction.

In the current study, we investigate the potential mediating role of motivational goals (as indicated by Archer's (1994) Achievement Goals scales), level of metacognitive awareness (as indicated by the Schraw and Dennison (1994) Metacognitive Awareness scales) and psychological adjustment (as indicated by Jackson's (1974) Need for Affiliation scale and the Watson and Friend (1969) FNE and SAD scales) on secondary students' evaluation of group-based learning and preparedness to engage in group-based learning environments.

\section{Method}

\section{Participants:}

290 students from Years 7, 9 and 11 from a high school in the Lower Hunter region of NSW took part in the study. The average age of the participants was 13.82 years (sd 1.57), with ages ranging from 12 through to 17. 


\section{Materials:}

Achievement Goals Questionnaire (Archer, 1994). These scales are designed to measure three achievement goals. Items are measured on 5-point Likert scales, with some items requesting feelings of success, some items requesting feelings of satisfaction, and some items requesting degrees of agreement. Eight items indicate the presence of a mastery goal. Examples of these items include feeling successful when a lesson made you think about things, and feeling satisfied when you were involved totally in something you were doing. Examples of the eight items indicating the presence of a performance goal include feeling successful when you got a higher mark than other students, and feeling satisfied when you received recognition or prestige. Examples of the four items indicating the presence of an alienation goal include feeling successful when you did almost no work and got away with it, and feeling satisfied when you realised you didn't have to prepare for classes. Alpha coefficients for the achievement goal scales in the current data were .82 for mastery, .86 for performance and .64 for alienation.

Metacognitive Awareness Inventory (MAI, Schraw \& Dennison, 1994). This instrument provides measures of two broad aspects of adolescents' and adults' metacognitive awareness: Knowledge of Cognition, including awareness of one's declarative, procedural and conditional knowledge of learning, and Regulation of Cognition, including awareness of the need for planning, information management, monitoring, debugging and evaluating. Examples of items indicating knowledge of cognition include: I understand my intellectual strengths and weaknesses (declarative knowledge)I; I try to use strategies that have worked in the past (procedural knowledge); I learn more when I'm interested i $n$ the topic (conditional knowledge). Examples of items indicating regulation of cognition include: I think about what I really need to learn before I begin a task (planning); I consciously focus my attention on important information (information management); I ask myself questions about how I am doing while I am learning something new (monitoring); I ask myself if I learned as much as I could have once I finish a task (evaluating). In the current study, the original 52 items were reduced to 20, with ten items in each scale. Reliability estimates (alphas) for the shortened form of the MAI in the current data were acceptably high: Knowledge of Cognition: .79; Regulation of Cognition: .84

Fear of Negative Evaluation and Social Avoidance and Distress Scale (Watson \& Friend, 1969). These instruments provide measures of reported levels of social anxiety. In the present study, the underlying structures of the FNE and SAD identified by Monfries and Kafer (1988; 1994) were utilised. Monfries and Kafer $(1988$; 1994) identified two factors within the FNE relating to self/other reactions to negative evaluation: the Negative Expectations (NE) sub-scale (13 items) indicating an inner fear of making oneself conspicuous by an inappropriate or embarrassing social performance, and the Negative Public Evaluation (NPE) (14 items) indicating a fear of other people perceiving a social performance to be inappropriate. Items within the FNE questionnaire 
include I feel really upset when I commit some sort of error (NE), and I am often afraid that I may look ridiculous or make a fool of myself (NPE). All items were presented on a five-point Likerttype scale. Monfries and Kafer's $(1988 ; 1994)$ analysis of the factor structure of the SAD revealed three distinct sub-scales: two relating to subjective evaluations of distress in familiar (DFG) (11 items) and unfamiliar groups (DUG) (5 items), and a third more pathological dimension of avoidance of groups (AG) (8 items). Items in the SAD scales included I often feel calm and comfortable at social situations (reverse scored, DFG); I am usually nervous with people unless I know them well (DUG); and I have no particular desire to avoid people (reverse scored, AG). Alpha coefficients for all scales in the current data were acceptably high (NE: .85; NPE: .77; DFG: .79; DUG: .56; AG: .77)

Need for Affiliation subscale from the PRF - Form E. (Jackson, 1974). This single scale instrument is designed to indicate an individual's level of sociability. Items are expressed as true or false for the individual. Sample items include I am quite independent of the people I know (negative valence), I choose hobbies that I can share with other people (positive valence), and Sometimes when a friend is in trouble, I cannot sleep because I want so much to help (positive valence). The alpha coefficient for this scale in the current data was acceptable at .64.

Feelings Towards Group Work. This instrument was developed specifically for this study. The questionnaire consists of 30 items presented as Likert items based on a five point scale of 1 indicating not at all true of me to 5 indicating very true of me. Five areas of group work were included in the instrument: a general liking of groups (I enjoy working within a group); group composition (I prefer working within a group of the same sex); self-efficacy in groups (I feel more accepted by others after working within a group); group dynamics (I usually make a strong personal contribution to group work); and group organisation (Groups should organise themselves so that the work is divided evenly). The instrument is appended to this report.

Factor Analysis of Feelings Towards Group Work Questionnaire: Data from the pilot questionnaire were subjected to principal components analysis using normalised varimax rotation. Analysis of the scree diagram suggested either three or four factors would reflect the underlying dimensionality of the instrument. Examination of item content biassed the decision towards a three factor solution. These factors are described below. Item inclusion within a scale was based upon two criteria: a factor loading of at least .40 and non-dual loading across factors.

Factor 1: Preference for individual learning. Seven items were included in the scale derived from this factor. The items intimate a strong feeling of dissatisfaction with group work, including feelings of being let down by group members, of seeing group work as confusing and less effective than individual learning, of preferring to work alone and expressing a lack of involvement and enjoyment in group situations. Reliability estimate for the seven item scale (Cronbach alpha) 
was .78.

Factor 2: Preference for group learning. Eight items were included in the scale derived from this factor. The items intimate a strong sense of commitment to and fulfilment in group learning situations - a sense of enhanced understanding, of enjoyment in sharing the responsibility for the workload and credit for group achievements, of a greater sense of personal contribution to learning combined with a preference for choice in group membership. Reliability estimate for the eight item scale was .71.

Factor 3: Discomfort in group learning. Four items were included in the scale derived from this factor. The items intimate a sense of discomfort when learning in a group context - feelings of nervousness and an inability to relax, a fear of asking for help, and difficulty in understanding the nature of group task. Reliability estimate for the four item scale was .60.

Additional measures. In addition to standard information of age, gender and year level, students were also asked to indicate their frequency of exposure to group work. Group work was defined for students as "two or more people working together". Frequency was indicated by checking one of five options: never, less than once a week, once a week, twice a week, more than twice a week.

\section{Procedures}

Data was obtained through arrangement with the school for in class testing to be undertaken. Information sheets were distributed to parents with attached consent forms returned to the school allowing for participation in the study. Approximately $90 \%$ of the students returned the signed consent form. Eighty minute blocks were set aside for classes to complete the questionnaires. Time of day varied according to individual class schedules. The second author was present for all testing sessions.

\section{Analysis}

All data were analysed using appropriate programs from the Statistica for Windows v5.1 package (Statsoft, 1998). Relationships among the three Feelings towards Group Work scales and between these scales and other measures of individual differences were estimated using zero-order correlations. The relative contributions of the measures of individual differences as well as the reported frequency of group work, gender and year level to explaining attitudes towards group work were estimated by hierarchical regression procedures.

\section{Results}

Intercorrelations among Feelings Towards Group Work scales. 
These are included in Table I. Overall, students reporting a preference for individual learning were more likely to report discomfort learning in a group context, while those reporting a preference for group learning were less likely to report discomfort in group learning. Not all of these relationships were stable across year levels. The dichotomising of individual versus group learning preference, for example, was only apparent Year 11students, although non-significantly so. A preference for group learning was significantly related to lower levels of discomfort in group learning among Year 9 and Year 11 respondents only.

------ Insert Table I about here

\section{Intercorrelations between Feelings Towards Group Work scales and measures of individual differences}

These are included in Table II. 


\section{Cognitive Measures}

Achievement Goals: Overall, students reporting both mastery goals and performance goals were likely to express a preference for group learning. These relationships were stronger amongst the Year 7 and Year 9 students. Preference for individual work was largely unrelated to either mastery or performance goals, while there was a general tendency for students reporting alienation goals to be less likely to prefer individual work. This latter relationship was significant only amongst Year 7 students. Achievement goals were unrelated to feelings of discomfort in group work.

Metacognitive Awareness: Both knowledge of cognition and regulation of cognition were significantly related to a preference for group learning across all year levels. Knowledge of cognition was also negatively related to feelings of discomfort in groups generally, although this relationship was weaker among the Year 7 respondents. There were no significant relationships between measures of metacognitive awareness and a preference for individual work.

\section{Psychological Measures}

Need for Affiliation: Overall the students reporting a high need for affiliation were more likely to express a preference for group learning, less likely to express a preference for individual learning, and less likely to experience discomfort in group learning. These relationships strengthened across year groups, with both Year 9 and Year 11 respondents more likely to link a low need for affiliation with a preference for individual work and discomfort in groups. The positive relationships between a high need for affiliation and a preference for group work was also confined to the Year 9 and 11 respondents.

Fear of Negative Evaluation: Neither of the FNE subscales were related to a preference for group work. The expectation of displaying socially inappropriate behaviours (NE) was related to a preference for individual work among Year 7 and Year 9 students, and to feelings of discomfort in groups among all respondents.

Social Avoidance and Distress: There was a general tendency for students reporting lower levels of social avoidance and distress (across all three subscales) to express a preference for group work. Year 7 students reporting distress in familiar groups and avoidance of groups were more likely to prefer individual work, while all students reporting distress in familiar groups and avoidance of groups, and less strongly distress in unfamiliar groups, reported greater discomfort in group work.

\section{Relative contributions of all measures of individual differences towards feelings towards group work}


In these analyses, all measured individual differences (including Frequency of Exposure to Group Work, Gender, Year level, Achievement Goals, Metacognitive Awareness, Need for Affiliation, Fear of Negative Evaluation, and Social Avoidance and Distress) were entered as blocks into a hierarchical regression model for each of the three scales indicating feelings towards group work. The correlation matrix on which these analyses were based is presented in Table III. Summaries of these analyses are presented in Table IV. The distribution of variance for each of the Feelings Towards Group Work scales are illustrated in Figure 1.

------ Insert Table III about here ------

Significant contributions towards explaining a preference for individual learning were restricted to the psychological measures: Social Avoidance and Distress (4.28\% of total variance), Fear of Negative Evaluation (9.62\%) and Need for Affiliation (1.34\%). Contributions towards explaining a preference for group learning, however, included both cognitive and psychological variables: Metacognitive Awareness (30.13\% of total variance, primarily attributable to Knowledge of Cognition), Achievement Goals (18.07\%, including both mastery and performance goals, but not alienation goals), Need for Affiliation (4.29\%) and Social Avoidance and Distress (2.67\%). Contributions towards explaining feelings of discomfort in group learning related mainly to psychological variables (Social Avoidance and Distress (26.77\%), Fear of Negative Evaluation (11.15\%) and Need for Affiliation (9.24\%) as well as to levels of Metacognitive Awareness (5.75\%).

------Insert Figure 1 about here ------

\section{Discussion}

Three basic attitudes underlying secondary students' feelings towards groups were identified in the analyses: a preference for individual learning, a preference of group learning, and a feeling of discomfort in groups. These findings appear to us to be defensible at both a theoretical and empirical level. Clearly not all students express a preference for working in groups, and many students indeed report the experience of group work to be quite discomforting. What also seems important in explaining these attitudes towards group learning is that the more intuitive explanatory factors of frequency of exposure, gender and year level appear to play only minor roles. Of much greater importance were the predicted underlying cognitive and psychological factors.

The relationships between the feelings towards group work scales and measures of individual differences suggested two clear patterns of association. On the one hand, students reporting a 
preference for group work were distinguished by higher levels of metacognitive awareness and more positive achievement goals. In other words, preference for group learning appears to relate primarily to cognitive rather than psychological factors. Students reporting a preference for individual learning and students reporting greater degrees of discomfort in group learning environments were distinguished by higher levels of social anxiety and lower levels of sociability, with some indication of a lower level of metacognitive awareness. In other words, discomfort in group learning appears to relate primarily to psychological rather than cognitive factors. At the more extreme level of discomfort, lack of metacognitive control would also appear important.

Both performance and mastery goals were associated with a preference for group learning. The mastery goal has been associated with a desire for achieving task-related competence, and with a willingness to invest effort to achieve this (e.g. Archer, Cantwell \& Bourke, 1997). The interplay of ideas generally associated with group work may well require both task orientation and effort expenditure, and as such may prove attractive to mastery oriented students. We expected students reporting performance goals to be less attracted to group work, primarily because of the inherent risk of exposure should the individual's competence be called into question in such an intimate environment. This did not prove to be the case in the present data. It may be that for these students, group work has not been associated with unduly threatening experiences. At a more theoretical level, we may also speculate that the lack of negative valence in the performance scale may mask the attitude of performance oriented students in failure rather than success situations.

The critical role of metacognitive awareness in explaining both a preference for group learning and discomfort in group learning suggests to us that there is a strong cognitive and strategic basis to effective group functioning. Taking learning from the individual to social setting adds significant dimensions of complexity. Clearly for those students with greater degrees of awareness of their own cognitive state and processes, self-regulatory control over such complexity is possible (Cantwell \& Monfries, 1993). For those students reporting lower levels of metacognitive awareness, the presumed lessening of self-regulatory control over complexity becomes associated with greater discomfort in group learning.

Where the cognitive aspects linked most closely to the expressed preference for group learning, psychological factors measured in this study were more strongly associated with both a preference for individual learning and feelings of discomfort in group learning. Need for affiliation as a measure of sociability was associated with both individual preference and discomfort. These associations suggest that for some students, there are basic personality factors that may well be working against participation in group based activities. The data relating to measures of social distress also indicated strong associations with feelings about group learning. Fear of displaying socially inappropriate behaviours in social contexts (the Negative Expectations subscale of the FNE) appeared a strong predictor of preference for individual learning and of distress in group learning for all participants. This contrasted with findings for the Negative Public Evaluation 
subscale where no significant associations were found. This may reflect an aspect of adolescent development in the sense that the NE subscale reflects internalised cognitions about the efficacy of one's own behaviour rather than the negative perceptions of other's responses to one's behaviour. To the extent that adolescent students are experiencing an Eriksonian identity crisis, negative selfefficacy judgements may well predict a lesser desire for socially based learning contexts. The data also indicated strong associations between higher levels of social avoidance and distress and a preference for individual learning and discomfort in group learning. In reference to those students preferring individual learning environments and students expressing discomfort in groups, associations were strongest with the Distress in Familiar Groups (DFG) subscale and the Avoidance of Groups (AG) subscale. There is little doubt that group work in secondary schools involves relatively intimate contact with well known individuals

. Unlike interaction with less familiar individuals, contact with familiar individuals involves more complex strategic behaviours - less can be avoided through the use of social cliches and algorithms. Not surprisingly, there was a significant correlation between DFG levels and Knowledge of Cognition: the greater the (social) cognitive demands, the greater the need for metacognitive control (although it should be noted that amongst Year 7 respondents there were significant links with DUG as well, perhaps reflecting one of the problems of transition to high school).

Overall the data indicate significant roles for both cognitive and psychological factors in explaining secondary students feelings towards group work. Encouragingly, however, there is research suggesting that a number of these factors are controllable by teacher actions (e.g Fantuzzo et al, 1989). If students can be encouraged to develop more sophisticated ways of addressing complexity - in both the cognitive and social cognitive domains - and if this can be achieved in a climate encouraging the development of mastery goals, then basic cognitive and psychological impediments to effective group functioning may be minimised.

\section{References}

Archer, J. (1994). Achievement goals as a measure of motivation in university students. Contemporary Educational Psychology. 19, 430-446.

Archer, J., Cantwell, R. \& Bourke, S. (1997).Academic performance of students from enabling programs: Some relationships. Paper presented at the 7th European Conference on Research on Learning and Instruction, Athens, August.

Ames, C. \& Archer, J. (1988). Achievement goals in the classroom setting: Students' strategies and motivational processes. Journal of Educational Psychology. 80, 260-267.

Cantwell, R. (1998). The development of beliefs about learning from mid- to late-adolescence. Educational Psychology. 18, 27-39.

Cantwell, R. \& Monfries, M. (1993, July). Cognitive correlates of social anxiety. Paper presented at the Australian and New Zealand Association for Medical Education Annual Conference, 
Suva, Fiji.

Fantuzzo, J., Riggio, R., Connelly, S. \& Dimeff, L. (1989). Effects of reciprocal peer tutoring on academic achievement and psychological adjustment: A component analysis. Journal of Educational Psychology. 81, 173-177.

Jackson, D. (1974). Personality Research Form Manual. Goshen, New York, McGraw Hill.

King, A. (1997). ASK to THINK TEL-WHY ® (C): A Model of transactive peer tutoring for scaffolding higher level complex learning. Educational Psychologist. 32, 221-235.

Klein, J. \& Pridemore, D. (1992). Effects of cooperative learning and need for affiliation on performance, time on task, and satisfaction. Educational Technology Research \& Development. 40, 39-47.

Monfries, M. \& Kafer, N. (1988). Dimensions of Social Anxiety. Paper presented to the 24th International Congress of Psychology, Sydney, Australia.

Monfries, M. \& Kafer, N. (1994). Private self-consciousness and fear of negative evaluation. The Journal of Psychology. 128, 447-454.

Palinscar, A. \& Brown, A. (1984). Reciprocal teaching of comprehension monitoring activities. Cognition and Instruction. 2, 117-175.

Schraw, G. \& Dennison, R.S. (1994). Assessing metacognitive awareness. Contemporary Educational Psychology. 19, 460-475

Schwanenflugel, P., Fabricius, W. \& Alexander, J. (1994). Developing theories of mind: Understanding concepts and relations between mental activities. Child Development. 65, 1546-1563.

Statsoft (1995/1998). Statistica for Windows v5.1 Tulsa, OK, Statsoft.

Slavin, R. (1996). Research on co-operative learning and achievement: what we know, what we need to know. Contemporary Educational Psychology. 21, 43-69.

Watson, D. \& Friend, R. (1969). Measurement of social-evaluative anxiety. Journal of Consulting and Clinical Psychology. 33, 448-457

Zimmermann, B. (1995). Attaining reciprocality between learning and development through selfregulation. Human Development, 38, 367-372.

Notes

1. This research was supported by the Griffith Duncan Fund, Faculty of Education, University of Newcastle.

2. The researchers gratefully acknowledge the support of staff and students of Maitland Grossman High School. Dr Jill Scevak is also acknowledged for her constructive comments.

3. An earlier version of this paper was presented at the European Conference on Developmental Psychology. Spetses, Greece, September 1999. 
Table I: Intercorrelations between Feelings About Group Work scales for the whole sample, and for Years 7, 9 and 11 separately.

\begin{tabular}{|c|c|c|c|c|c|c|c|c|c|c|c|c|}
\hline \multirow[b]{2}{*}{ Feelings about Group Work } & \multicolumn{4}{|c|}{$\begin{array}{c}\text { Preference for individual } \\
\text { learning }\end{array}$} & \multicolumn{4}{|c|}{ Preference for group learning } & \multicolumn{4}{|c|}{ Discomfort in group learning } \\
\hline & All & Yr 7 & Yr 9 & Yr11 & All & Yr 7 & Yr 9 & Yr11 & All & Yr 7 & Yr 9 & Yr11 \\
\hline 1. Preference for individual learning & -- & -- & -- & -- & -01 & 07 & -01 & -22 & $42 * * *$ & $44 * * *$ & $45^{* * *}$ & $35^{*}$ \\
\hline 2. Preference for group learning & -01 & .07 & -01 & -22 & -- & -- & -- & -- & $-19 * *$ & -12 & $-21 *$ & $-39 *$ \\
\hline 3. Discomfort in group learning & $42 * *$ & $44^{* *}$ & $45^{* *}$ & $35 *$ & $-19 * *$ & -12 & $-21^{*}$ & $-39 *$ & -- & -- & -- & -- \\
\hline
\end{tabular}

Note: $\quad$ Decimal points removed. Sample sizes: All subjects $=290$; Year $7=134$; Year $9=99$; N for Year $11=57$.

$* p<.05 \quad * * p<.01 * * * p<.001$ 
Table II: Intercorrelations between Feelings About Group Work scales and measures of individual differences for the whole sample, and for Years 7, 9 and 11 separately.

\begin{tabular}{|c|c|c|c|c|c|c|c|c|c|c|c|c|}
\hline \multirow[b]{3}{*}{ Measure of Individual Difference } & \multicolumn{12}{|c|}{ Feelings About Group Work Scales } \\
\hline & \multicolumn{4}{|c|}{$\begin{array}{c}\text { Preference for individual } \\
\text { learning }\end{array}$} & \multicolumn{4}{|c|}{ Preference for group learning } & \multicolumn{4}{|c|}{ Discomfort in groups } \\
\hline & All & Yr 7 & Yr 9 & $\begin{array}{l}\mathrm{Yr} \\
11 \\
\end{array}$ & All & Yr 7 & Yr 9 & Yr11 & All & Yr 7 & Yr 9 & Yr11 \\
\hline \multicolumn{13}{|l|}{ Achievement Goals } \\
\hline Mastery Goal & 11 & $18^{*}$ & -02 & 18 & $38 * * *$ & $42 * * *$ & $45^{* * *}$ & 21 & -10 & -14 & -17 & 17 \\
\hline Performance Goal & 07 & 07 & 05 & 12 & $36 * * *$ & $37 * * *$ & $48 * * *$ & 21 & -06 & -07 & -13 & 09 \\
\hline Alienation Goal & -06 & $-18 *$ & -01 & 08 & 01 & -02 & 18 & -11 & -03 & -04 & -04 & 09 \\
\hline \multicolumn{13}{|l|}{ Metacognitive Awareness } \\
\hline Knowledge of Cognition & 04 & 12 & -03 & -03 & $54 * * *$ & $49 * * *$ & $62 * * *$ & $55 * * *$ & $-21 * * *$ & -12 & $-31 * * *$ & -23 \\
\hline Regulation of Cognition & 11 & 13 & 09 & 06 & $43^{* * *}$ & $37 * * *$ & $55^{* * *}$ & $44^{* *}$ & -01 & 01 & 07 & -21 \\
\hline Need for Affiliation & $-12^{*}$ & 01 & $-20^{*}$ & -21 & $21^{* * *}$ & 16 & $27^{* *}$ & 21 & $-31 * * *$ & -15 & $-48 * * *$ & $-40 * *$ \\
\hline \multicolumn{13}{|l|}{ Fear of Negative Evaluation } \\
\hline Negative Expectations & $26 * * *$ & $34 * * *$ & $31^{* *}$ & 04 & 07 & 06 & 03 & 19 & $30 * * *$ & $32 * * *$ & $24 *$ & $34 * *$ \\
\hline Negative Public Evaluation & -03 & 08 & -05 & -17 & 02 & -08 & 05 & 19 & 03 & -04 & -02 & 19 \\
\hline \multicolumn{13}{|l|}{ Social Avoidance and Distress } \\
\hline Distress in Familiar Groups & $21^{* * *}$ & $34 * * *$ & 09 & 17 & $-18 * *$ & -14 & $-21^{*}$ & -23 & $49 * * *$ & $49 * * *$ & $47 * * *$ & $54 * * *$ \\
\hline Distress in Unfamiliar Groups & 03 & 11 & -03 & -01 & $-13^{*}$ & $-20 *$ & -07 & -06 & $22 * * *$ & $20 *$ & 15 & $37 * *$ \\
\hline Avoidance of Groups & $18 * *$ & $30 * * *$ & 03 & 21 & $-18^{* *}$ & -14 & $-22 *$ & -23 & $50 * * *$ & $51 * * *$ & $51 * * *$ & $48 * * *$ \\
\hline
\end{tabular}

Note: $\quad$ Decimal point removed. Sample sizes: All subjects = 290; Year $7=134 ;$ Year 9 = 99; N for Year $11=57$.

$* p<.05 \quad * * p<.01 * * * p<.001$ 
Table III: Intercorrelations between all measures of individual differences for whole sample

\begin{tabular}{|c|c|c|c|c|c|c|c|c|c|c|c|c|c|c|}
\hline & 1 & 2 & 3 & 4 & 5 & 6 & 7 & 8 & 9 & 10 & 11 & 12 & 13 & 14 \\
\hline 1. Mastery Goals & 1.00 & & & & & & & & & & & & & \\
\hline 2. Performance Goals & $.50 * *$ & 1.00 & & & & & & & & & & & & \\
\hline 3. Alienation Goals & .09 & $.21 * *$ & 1.00 & & & & & & & & & & & \\
\hline 4. Regulation of Cognition & $.39 * *$ & $.29 * *$ & -.07 & 1.00 & & & & & & & & & & \\
\hline 5. Knowledge of Cognition & $.49 * *$ & $.47 * *$ & -.01 & $.63^{* *}$ & 1.00 & & & & & & & & & \\
\hline 6. Need for Affiliation & $.20 * *$ & $.14^{*}$ & -.00 & $.17 *$ & $.23 * *$ & 1.00 & & & & & & & & \\
\hline 7. Negative Expectations & .05 & .07 & -.02 & .15 & .06 & $-.13 *$ & 1.00 & & & & & & & \\
\hline 8. Negative Public Evaluation & -.01 & -.03 & $-.14^{*}$ & -.08 & -.09 & -.07 & $.52 * *$ & 1.00 & & & & & & \\
\hline 9. Distress in Familiar Groups & $-.16 * *$ & $-.17^{* *}$ & -.02 & -.04 & $-.22 * *$ & $-.43 * *$ & $.27 * *$ & $.22 * *$ & 1.00 & & & & & \\
\hline 10. Distress in Unfamiliar Groups & -.11 & -.10 & -.01 & -.09 & -.10 & $-.23 * *$ & $.22 * *$ & $.28 * *$ & $.54 * *$ & 1.00 & & & & \\
\hline 11. Avoidance of Groups & $-.14^{*}$ & $-.14^{*}$ & -.05 & -.05 & $-.15^{*}$ & $-.39 * *$ & $.23 * *$ & $.18^{* *}$ & $.79 * *$ & $.41 * *$ & 1.00 & & & \\
\hline 12. Preference for Individual Work & -.03 & -.05 & $-.16^{*}$ & -.10 & -.06 & $-.12 *$ & $.27 * *$ & $.15^{* *}$ & $.40 * *$ & $.21 * *$ & $.38 * *$ & 1.00 & & \\
\hline 13. Preference for Group Work & $.50 * *$ & $.47 * *$ & .04 & $.47 * *$ & $.62 * *$ & $.21 * *$ & .08 & -.02 & $-.29 * *$ & $-.20 * *$ & $-.30 * *$ & $-.30 * *$ & 1.00 & \\
\hline 14. Discomfort in Groups & $-.12 *$ & -.09 & .02 & -.00 & $-.24 * *$ & $-.31 * *$ & $.34 * *$ & .04 & $.50 * *$ & $.25 * *$ & $.38 * *$ & $.38 * *$ & $-.23 * *$ & 1.00 \\
\hline
\end{tabular}

$* p<.05 \quad * * p<.01$ 
Table IV: Relative contribution of all measures of individual differences towards feelings about group work

\begin{tabular}{|c|c|c|c|c|}
\hline Outcome variable & Predictor variable & Semi-partial $^{2}$ & Unique & Total \\
\hline \multirow{18}{*}{$\begin{array}{l}\text { Preference for } \\
\text { individual learning }\end{array}$} & Frequency of exposure & - & 0.00 & 0.00 \\
\hline & Gender & - & 0.00 & 0.00 \\
\hline & Year & - & 0.00 & 0.00 \\
\hline & Achievement Goals & & 2.59 & 1.80 \\
\hline & * Mastery Goals & .01 & & \\
\hline & * Performance Goals & .00 & & \\
\hline & * Alienation Goals & .01 & & \\
\hline & Metacognitive Awareness & & 0.01 & 0.06 \\
\hline & * Knowledge of Cognition & .00 & & \\
\hline & * Regulation of Cognition & .01 & & \\
\hline & Need for Affiliation & & 0.02 & $1.34 *$ \\
\hline & Fear of Negative Evaluation & & $7.31^{* * *}$ & $9.62 * * *$ \\
\hline & * Negative Expectations & $.10^{* * *}$ & & \\
\hline & * Negative Public Evaluation & $.04 * * *$ & & \\
\hline & Social Avoidance and Distress & & $2.41^{*}$ & $4.28 * *$ \\
\hline & * Distress in Familiar Groups & $.02 *$ & & \\
\hline & * Distress in Unfamiliar Groups & .01 & & \\
\hline & * Avoidance of Groups & .00 & & \\
\hline \multirow{18}{*}{$\begin{array}{l}\text { Preference for group } \\
\text { learning }\end{array}$} & Frequency of exposure & & 0.01 & 0.01 \\
\hline & Gender & & 0.12 & 0.19 \\
\hline & Year & & 0.59 & 0.48 \\
\hline & Achievement Goals & & $2.11 *$ & $18.07 * * *$ \\
\hline & * Mastery Goals & $.05 * * *$ & & \\
\hline & * Performance Goals & $.04 * * *$ & & \\
\hline & * Alienation Goals & .00 & & \\
\hline & Metacognitive Awareness & & $12.21^{* * *}$ & $30.13^{* * *}$ \\
\hline & * Knowledge of Cognition & $.16^{* * *}$ & & \\
\hline & * Regulation of Cognition & $.01^{*}$ & & \\
\hline & Need for Affiliation & & 0.19 & $4.29 * *$ \\
\hline & Fear of Negative Evaluation & & 0.78 & 0.62 \\
\hline & * Negative Expectations & .01 & & \\
\hline & * Negative Public Evaluation & .00 & & \\
\hline & Social Avoidance and Distress & & & \\
\hline & * Distress in Familiar Groups & .00 & 0.89 & $2.67^{*}$ \\
\hline & * Distress in Unfamiliar Groups & .00 & & \\
\hline & * Avoidance of Groups & .00 & & \\
\hline \multirow{18}{*}{$\begin{array}{l}\text { Discomfort in group } \\
\text { learning }\end{array}$} & Frequency of exposure & & 0.03 & 0.05 \\
\hline & Gender & & 0.04 & 0.06 \\
\hline & Year & & 0.00 & 0.06 \\
\hline & Achievement Goals & & 0.06 & 0.09 \\
\hline & * Mastery Goals & .01 & & \\
\hline & * Performance Goals & .00 & & \\
\hline & * Alienation Goals & .00 & & \\
\hline & Metacognitive Awareness & & $2.63 * *$ & $5.75^{* * *}$ \\
\hline & * Knowledge of Cognition & $.06 * * *$ & & \\
\hline & * Regulation of Cognition & $.02 *$ & & \\
\hline & Need for Affiliation & & 0.47 & $9.24 * * *$ \\
\hline & Fear of Negative Evaluation & & $6.55^{* * *}$ & $11.15^{* * *}$ \\
\hline & * Negative Expectations & $.11^{* * *}$ & & \\
\hline & * Negative Public Evaluation & $.02^{* *}$ & & \\
\hline & Social Avoidance and Distress & & $14.17^{* * *}$ & $26.77 * * *$ \\
\hline & * Distress in Familiar Groups & $.02 * *$ & & \\
\hline & * Distress in Unfamiliar Groups & .00 & & \\
\hline & * Avoidance of Groups & $.03^{* * *}$ & & \\
\hline
\end{tabular}

\section{Feelings Towards Group Work}


This questionnaire contains a number of statements about how you might feel about working in groups. If you feel the statement is very true of you, circle the " 5 ". If you feel the statement is not true of you at all, circle the "1" If you feel the statement is partly true of you, circle the "2" " 3 " or " 4 ". Remember that there are no right or wrong answers.

Please respond to all statements.

\begin{tabular}{|c|c|}
\hline & $\begin{array}{|lc|}\begin{array}{l}\text { Never } \\
\text { true of me }\end{array} & \begin{array}{c}\text { Always true } \\
\text { of me }\end{array} \\
\end{array}$ \\
\hline 1. I enjoy working within a group (I) * & $1-2-3-4-5$ \\
\hline 2. I prefer working within a group of the same sex & \\
\hline 3. I sometimes feel nervous when I have to give my ideas or communicate & \\
\hline within a group (D) & $1-2-3-4-5$ \\
\hline 4. I understand information better after explaining it to others in a group (G) & $1-2-3-4-5$ \\
\hline 5. I feel more accepted by others after working within a group & $1-2-3-4-5$ \\
\hline 6. I often find it difficult to understand what the group task is (D) & $1-2-3-4-5$ \\
\hline 7. I like to work alone even when placed in a group (I) & $1-2-3-4-5$ \\
\hline 8. I think groups should take the time to set up group goals & $1-2-3-4-5$ \\
\hline 9. I prefer to work within a group rather than work alone (I) * & $1-2-3-4-5$ \\
\hline 10. I prefer to work in groups of mixed sex & $1-2-3-4-5$ \\
\hline 11. Even when the group is achieving its goals, I don't really feel involved or & \\
\hline & $1-2-3$ \\
\hline 12. I often have a strong feeling satisfaction when I become totally involved in & \\
\hline $\begin{array}{l}\text { a group achievement (G) } \\
\text { 13. It is important that other group members take resnonsibility for my leal }\end{array}$ & $1-2-3-4-5$ \\
\hline $\begin{array}{l}\text { 13. It is important that other group members take responsibility for my learning } \\
\text { as well (G) }\end{array}$ & $1-2-3-4-5$ \\
\hline 14. I don't like it when one member of the group takes over from everyone else & $1-2-3-4-5$ \\
\hline & $1-2-3-4-5$ \\
\hline 16. I usually make a strong personal contribution to group work $(\mathrm{G})$ & $1-2-3-4-5$ \\
\hline 17. I am often afraid to ask for help within my group (D) & $1-2-3-4-5$ \\
\hline 18. I often feel less motivated to learn within a small group & $1-2-3-4-5$ \\
\hline 19. I like group work more when we can make up our own gro & $1-2-3-4-5$ \\
\hline 20. I do not like to study within a group (I) & $1-2-3-4-5$ \\
\hline 21. Contributing ideas within a group often makes me feel better about myself & $1-2-3-4-5$ \\
\hline 22. I can usually understand other group members' ideas (G) & $1-2-3-4-5$ \\
\hline 23. Even when groups are well organised, I don't believe they are a more & \\
\hline effective way of using class time (I) & $1-2-3-4-5$ \\
\hline 24. It is best when each person helps each other within a group (G) & $1-2-3-4-5$ \\
\hline 25. I often think the work becomes too confusing when done in a group rather & \\
\hline than individually (I) & 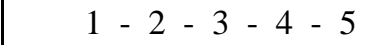 \\
\hline 26. Group work is better when the teacher tells us which groups to go in to & $1-2$ \\
\hline I relaxed within a group ( & $1-2-3-4-5$ \\
\hline 28. I do not feel responsible for othe & \\
\hline 29. I sometimes feel let down by other group members (I) & $1-2-3-4-5$ \\
\hline 30. I often feel in charge when working within a group & $1-2-3-4-5$ \\
\hline
\end{tabular}

Note: $\quad$ (I) $=$ included in scale Preference for Individual Work

(G) = included in scale Preference for Group Work

(D) = included in scale Discomfort in Group Work

* = item reverse scored for that scale 
List of Figures

Figure 1: Distribution of Total Variance for each of the Feelings Towards Group Work scales 


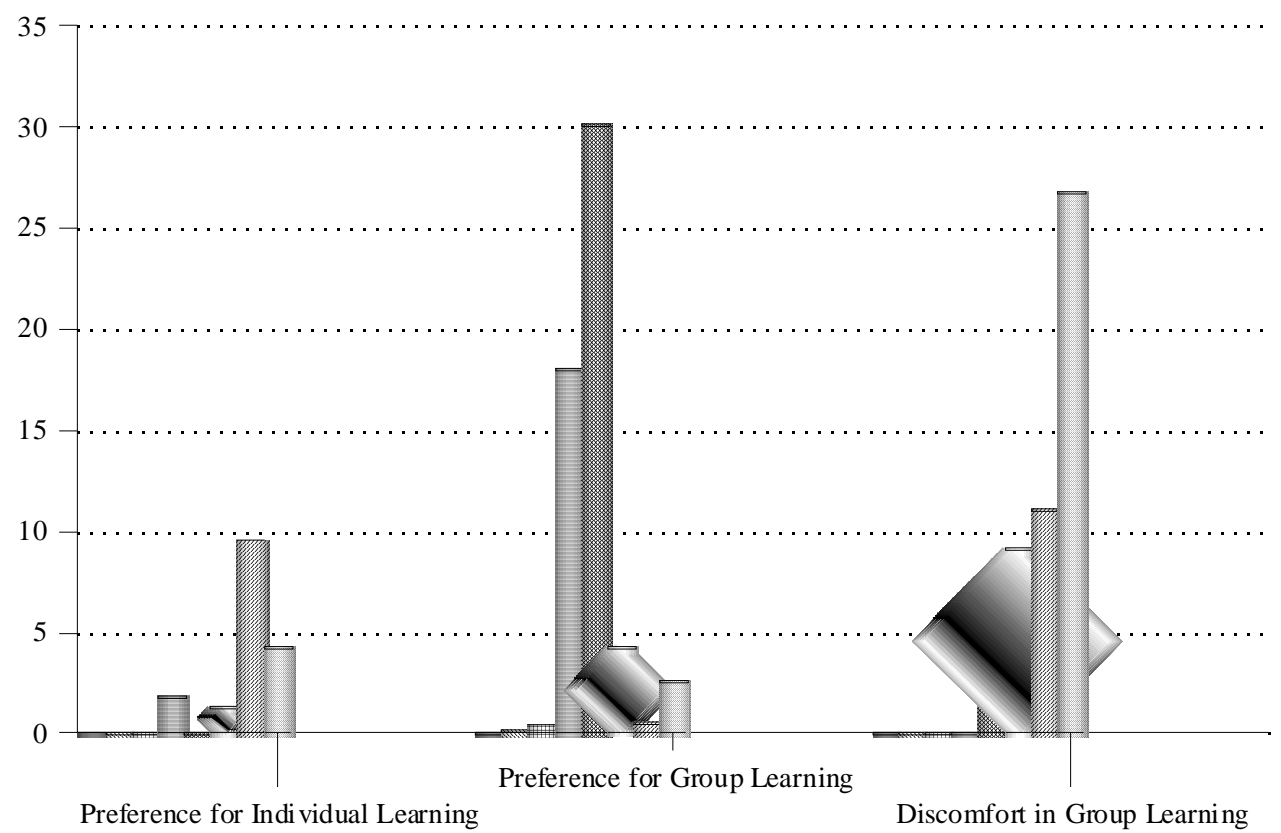

Preference for Individual Learning

$\square$ Frequency

Gender

Year
Achi evement Goals

MetacognitiveAwareness

Need for Affiliation

Fear of Negative Evaluation

Social Avoidance and Distress 
